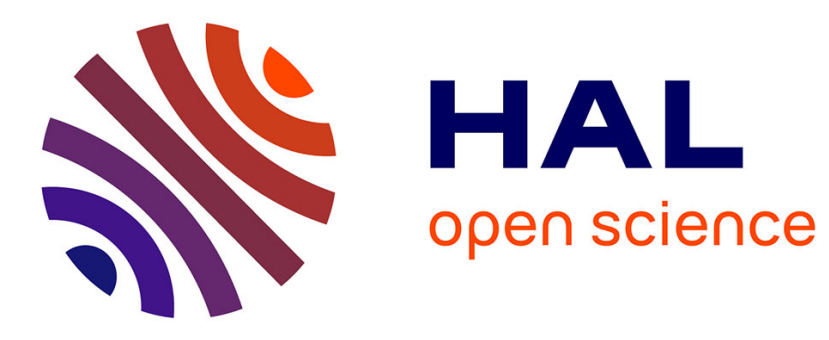

\title{
Early steps in layer-by-layer construction of polyelectrolyte films: The transition from surface/polymer to polymer/polymer determining interactions
}

\author{
C.C. Buron, C. Filiâtre, F. Membrey, C. Bainier, D. Charraut, A. Foissy
}

\section{To cite this version:}

C.C. Buron, C. Filiâtre, F. Membrey, C. Bainier, D. Charraut, et al.. Early steps in layer-bylayer construction of polyelectrolyte films: The transition from surface/polymer to polymer/polymer determining interactions. Journal of Colloid and Interface Science, 2007, 314 (2), pp.358-366. 10.1016/j.jcis.2007.05.060 . hal-00172168

\section{HAL Id: hal-00172168 \\ https://hal.science/hal-00172168}

Submitted on 17 Apr 2021

HAL is a multi-disciplinary open access archive for the deposit and dissemination of scientific research documents, whether they are published or not. The documents may come from teaching and research institutions in France or abroad, or from public or private research centers.
L'archive ouverte pluridisciplinaire HAL, est destinée au dépôt et à la diffusion de documents scientifiques de niveau recherche, publiés ou non, émanant des établissements d'enseignement et de recherche français ou étrangers, des laboratoires publics ou privés. 


\title{
Early steps in layer-by-layer construction of polyelectrolyte films: The transition from surface/polymer to polymer/polymer determining interactions
}

\author{
C.C. Buron ${ }^{\mathrm{a}}$, C. Filiâtre ${ }^{\mathrm{a}, *}$, F. Membrey ${ }^{\mathrm{a}}$, C. Bainier ${ }^{\mathrm{b}}$, D. Charraut $^{\mathrm{b}}$, A. Foissy ${ }^{\mathrm{a}}$ \\ a Institut UTINAM-CNRS 6213, Université de Franche-Comté, Besançon, France \\ b FEMTO-ST, Département d'Optique LOPMD, CNRS/Université de Franche-Comté, Besançon, France
}

\begin{abstract}
The layer-by-layer deposition of two polyelectrolytes, quaternized poly(dimethylaminoethyl methacrylate chloride) (MADQUAT) and poly(acrylic acid) (PAA) on a silica substrate was investigated using optical reflectometry, as a function of $\mathrm{pH}\left(\mathrm{pH} 4,5.5\right.$ and 9), ionic strength $\left(10^{-3}\right.$ to $10^{-1} \mathrm{M}$ ) and type of salt. Attention was given to the successive deposited weights and to the corresponding deposited charge densities within the ten first deposited layers. Results show a change of growth regime between an early stage where the substrate had a dominating influence in the build-up and a second stage where the polymer uptake was ruled essentially by polymer-polymer interactions. The $\mathrm{pH}$ was seen to influence the growth via the charge densities of silica (first stage) and PAA (first and second stages). The increase of $\mathrm{NaCl}$ concentration induced an increase of the film weight between $10^{-3}$ and $10^{-2} \mathrm{M}$, but the trend was more sophisticated between $10^{-2}$ and $10^{-1} \mathrm{M}$ where the polymer uptake increased in the first stage of the growth and decreased in subsequent layers. The film weight increased in accordance with the rank of ions in the Hofmeister series. AFM images revealed a heterogeneous film morphology with bumps and valleys, which was explained by a growth mechanism made of the successive formation and growth of polymer complexes.
\end{abstract}

Keywords: Polyelectrolyte multilayers; Layer-by-layer adsorption; pH influence; Ionic strength influence; Poly(acrylic acid); Poly(dimethylaminoethyl methacrylate chloride)

\section{Introduction}

Polyelectrolyte multilayers (PEM) prepared by stepwise and alternate adsorption from dilute polycation/polyanion solutions (also called layer-by-layer or LBL deposits) have been a very intense field of research since they were first described in the early nineties [1,2]. The interest for the LBL process is certainly related to its simplicity and to the many potential applications in a large number of fields [3]. However, in comparison with this intensive research, there have been few industrial achievements yet, which is explained by the lack of practical control of the process. Recent reviews show that many theoretical and practical aspects of the interaction parameters during the growth of

\footnotetext{
* Corresponding author.

E-mail address: claudine.filiatre@univ-fcomte.fr (C. Filiâtre).
}

the polymer films remain ambiguous and debated [4,5]. It is necessary to gain better knowledge in the dependence of the film construction on the main processing parameters, principally the $\mathrm{pH}$ when one of the polymer is a weak acid or base, the ionic strength and the type of salt. Among others, an important question addresses the early growth of LBL deposits, which concerns more or less the five first bilayers. Several investigators have shown a transition in growth rates (i.e., the deposited weight or layer thickness as a function of layer number) between a precursor regime and the "regular" growth regime within the first bilayers [6-8]. Also it was found that the properties of the first deposited layers affected considerably the properties of the whole PEM. As an example it is known that the preliminary deposition of poly(ethylene imine) on the substrate enhances the stability of the LBL film [9-11]. Our objective in the present work was to better understand the mechanism in- 
volved in the first stage of the successive polymer uptakes and to rationalize the influence of major parameters: charge of the substrate, $\mathrm{pH}$ and salt content.

In another work we addressed the influence of $\mathrm{pH}$ and salt concentration on the progressive weight uptake of alternating layers of a weak cationic polyelectrolyte poly(allylamine, $\mathrm{HCl}$ ) (PAH) and a strong polyacid poly(styrene sulfonic acid, sodium salt) (PSS) [12] on colloidal silica. A lot of information could be drawn from the charge balance between the two polymers in each bilayer, revealing the large contribution of the electrolyte (counter) ions in the neutralization of the polymer electrical charges.

In this investigation we aimed to analyze the reverse case of a strong cationic polymer, quaternized poly(dimethylaminoethyl methacrylate chloride) (MADQUAT) and a weak polyacid, poly(acrylic acid) (PAA). The amount of deposited polymer was measured step by step using optical fixed-angle reflectometry on a silica wafer. The charge balance in the film was computed and interpreted in terms of surface-polymer and polymer-polymer interactions at different $\mathrm{pH}$ and salt compositions. Finally, representative AFM pictures of polymer films were made to illustrate and support our description of the early growth mechanism of PEM.

\section{Experimental}

\subsection{Materials}

The quaternized poly(dimethylaminoethyl methacrylate chloride) (MADQUAT) and poly(acrylic acid) (PAA), see Fig. 1, were prepared by COATEX (France). The average molecular weight was respectively 30,000 and 10,000 Da. The refractive index increment $(\mathrm{d} n / \mathrm{d} c)$ of each polyelectrolyte was $0.192 \mathrm{~cm}^{3} \mathrm{~g}^{-1}$ for MADQUAT and $0.201 \mathrm{~cm}^{3} \mathrm{~g}^{-1}$ for PAA (Mettler Toledo refractometer RE50). The different salts employed were purchased from Aldrich.

\subsection{Polyelectrolyte film preparation}

The polyelectrolyte films were grown in the reflectometric cell on an oxidized silicon wafer (Applications Couches

\section{MADQUAT}

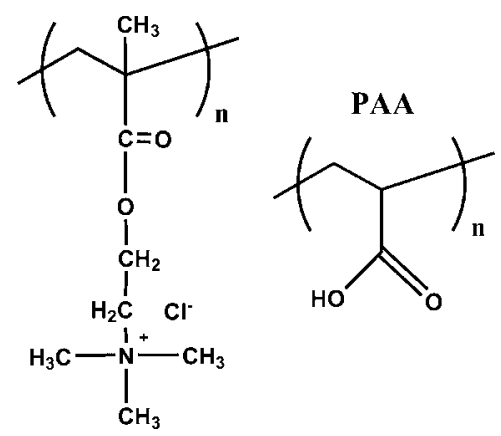

Fig. 1. Chemical formulas of the polymers: quaternized poly(dimethylaminoethyl methacrylate chloride) (MADQUAT) and the anionic poly(acrylic acid) (PAA).
Minces, ACM, France) with different silicon oxide layer thicknesses. The wafers were cleaned with a piranha solution $(7: 3$ v/v $\mathrm{H}_{2} \mathrm{SO}_{4}, 98 \%$ and $\mathrm{H}_{2} \mathrm{O}_{2}, 32 \%$ mixture), extensively washed with ultra-pure water (Milli-Q water, $18.2 \mathrm{M} \Omega \mathrm{cm}$ ) and finally stored in water until use. The two polymers were deposited by alternate injection of a solution of concentration $10 \mathrm{mg} \mathrm{L}^{-1}$ every $10 \mathrm{~min}$. No washing was made between each deposition step. Due to the negative charge of the silicon oxide surface, MADQUAT was deposited first.

\subsection{Optical fixed-angle reflectometry measurements}

The multilayer growth was monitored in situ by optical fixed-angle reflectometry using home made impinging jet cell $[13,14]$. The output of the reflectometer is given as $S / S_{0}-1=$ $\Delta S / S_{0}$, which depends both on the mean thickness and the refractive index of the deposited polymer film. In many cases the reflectometric signal is fairly proportional to the deposited weight of the polymer. We showed formerly that the upper limit of linearity for monolayers of polymers was a few $\mathrm{mg} \mathrm{m}^{-2}$ [15]. In the case of multilayers one may appropriately consider the change of output as a relative change of adsorbed polymer, which we shall do partly in this paper, but it is not right to assume straightforwardly a proportional change of deposited weight $[15,16]$. In order to compute step by step the mass and the charge balance, we have used a procedure described previously that allows the separate determination of the thickness and the refractive index of the deposited film [17]. When combined, these two values give the average deposited weight of the whole polymer film. Briefly, the principle of the method is to perform at least two similar deposition series (i.e., using precisely the same deposition conditions) on two chemically similar substrates with different thicknesses. In the present study we repeated exactly the same deposition experiments on silicon wafers with four different silicon oxide thicknesses $(52.9,98.7$, $138.5,163.5 \mathrm{~nm})$.

\subsection{AFM measurements}

The scanning probe microscope used in these experiments was a commercial AFM (Atomic Force Microscope) manufactured by NT-MDT. AFM pictures were made first with wet samples after the completion of the multilayers using the contact mode. They were repeated after drying the samples under nitrogen flow and in the tapping mode. In both cases, AFM images were recorded at the stagnation point (due to the design of the reflectometric cell) where molecules were transported by diffusion only to the substrate.

\section{Results}

\section{1. $p H$ dependence}

The influence of $\mathrm{pH}$ in the build-up of 5 bilayers is presented in Fig. 2 in the form of the reflectometric output at $\mathrm{pH} 4,5.5$ and 9 in $10^{-3} \mathrm{M} \mathrm{NaCl}$ solutions. As the level of the output is relatively bound to the deposited amount (see Section 2), we see 
Table 1

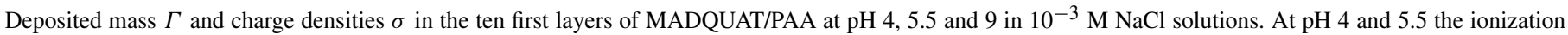
ratios used for the calculation are 0.15 and 0.5 , respectively

\begin{tabular}{|c|c|c|c|c|c|c|}
\hline \multirow{3}{*}{$\begin{array}{l}\text { Layer } \\
\text { number }\end{array}$} & \multicolumn{6}{|l|}{$\mathrm{NaCl} 10^{-3} \mathrm{M}$} \\
\hline & \multicolumn{2}{|l|}{$\mathrm{pH} 4$} & \multicolumn{2}{|l|}{$\mathrm{pH} 5.5$} & \multicolumn{2}{|l|}{$\mathrm{pH} 9$} \\
\hline & $\overline{\Gamma\left(\mathrm{mg} \mathrm{m}^{-2}\right)}$ & $\sigma\left(\mathrm{C} \mathrm{m}^{-2}\right)$ & $\overline{\Gamma\left(\mathrm{mg} \mathrm{m}^{-2}\right)}$ & $\sigma\left(\mathrm{Cm}^{-2}\right)$ & $\overline{\Gamma\left(\mathrm{mg} \mathrm{m}^{-2}\right)}$ & $\sigma\left(\mathrm{Cm}^{-2}\right)$ \\
\hline 0 & & $\approx 0$ & & $\approx 0$ & & -0.06 \\
\hline 1 & 0.039 & +0.019 & 0.063 & +0.030 & 0.154 & +0.074 \\
\hline 2 & 0.073 & -0.011 & 0.078 & -0.041 & 0.0153 & -0.016 \\
\hline 3 & 0.093 & +0.045 & 0.091 & +0.044 & 0.144 & +0.069 \\
\hline 4 & 0.24 & -0.037 & 0.185 & -0.098 & 0.018 & -0.019 \\
\hline 5 & 0.35 & +0.17 & 0.078 & +0.038 & $0.070^{\mathrm{a}}$ & +0.033 \\
\hline 6 & 0.94 & -0.15 & 0.38 & -0.20 & 0.034 & -0.036 \\
\hline 7 & 1.56 & +0.75 & $0.26^{\mathrm{a}}$ & +0.12 & 0.046 & +0.022 \\
\hline 8 & 3.18 & -0.49 & 0.28 & -0.15 & 0.034 & -0.036 \\
\hline 9 & 6.19 & +2.97 & 1.01 & +0.49 & 0.035 & +0.017 \\
\hline 10 & 10.6 & -1.64 & 0.91 & -0.48 & 0.063 & -0.067 \\
\hline \multicolumn{7}{|c|}{ Total weights $\left(\mathrm{mg} \mathrm{m}^{-2}\right)$} \\
\hline MADQUAT & 8.2 & & 1.5 & & 0.44 & \\
\hline PAA & 15.1 & & 1.8 & & 0.16 & \\
\hline Total & 23.3 & & 3.3 & & 0.6 & \\
\hline
\end{tabular}

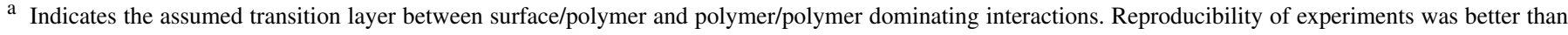
$5 \%$ in all cases.

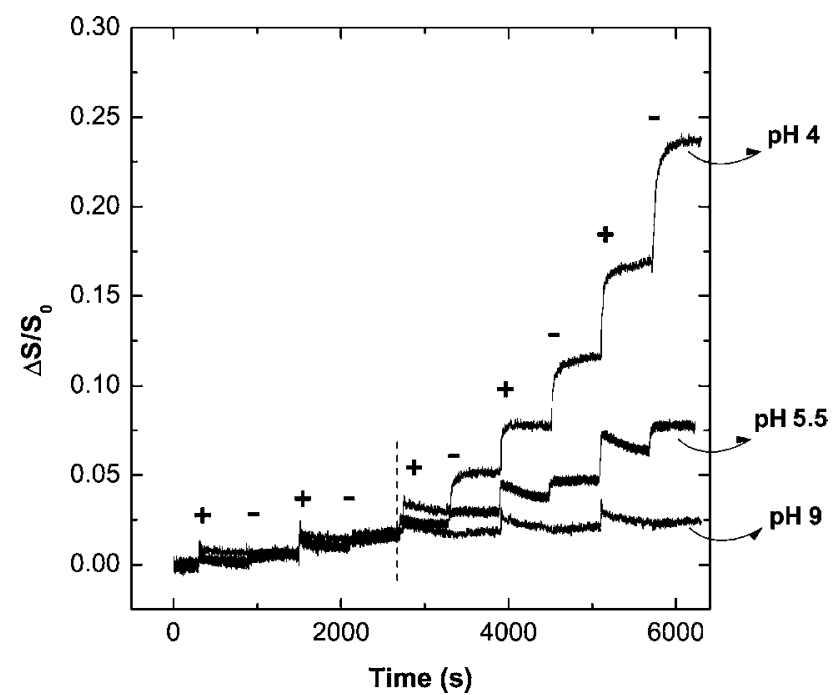

Fig. 2. Reflectometric output variation in function of $\mathrm{pH}$ solution during the multilayer formation. Experimental parameters: polyelectrolyte concentration $0.01 \mathrm{~g} \mathrm{~L}^{-1}$, salt and concentration $\mathrm{NaCl} 10^{-3} \mathrm{M}$.

clearly a considerable increase of adsorption of the two polymers when the $\mathrm{pH}$ decreased (from $0.6 \mathrm{mg} \mathrm{m}^{-2}$ at $\mathrm{pH} 9$ to $23.3 \mathrm{mg} \mathrm{m}^{-2}$ at $\mathrm{pH} \mathrm{4}$, see Table 1 ), which was certainly due to the decrease of the charge density of PAA since, as shown in the later discussion, the two polymers neutralized roughly each other within each successive bilayer. At pH 9 PAA was fully ionized, at pH 5.5 and 4 the ionization ratio was about 0.5 and 0.15 , respectively, but it was not known precisely as it depends on the salt type, the salt concentration and the binding ratio with the aminated groups in MADQUAT [18,19]. Thus, at lower $\mathrm{pH}$ more PAA could accumulate on the surface before reaching neutralization of the excess of positive charge in the formerly deposited MADQUAT layer. Due to the polymer/polymer uptake dependence (see Section 3.5), an increase of the adsorption of PAA lead to an increase for the adsorption of MADQUAT. In addition to the electrostatic interaction there was probably a contribution in the bonding energy of an hydrogen bond between the functional group $-\mathrm{COOH}$ in PAA and $-\mathrm{C}=\mathrm{O}$ in MADQUAT, which would explain the strong adsorption of PAA at pH 4 in spite of its low charge density. Therefore, the major contribution in the driving force for the binding between PAA and MADQUAT changed gradually from hydrogen bonding at low $\mathrm{pH}$ to electrostatic interactions at high $\mathrm{pH}$. Note also that the film composition changed with $\mathrm{pH}$. At $\mathrm{pH} 4$ PAA made $65 \%$ of the film weight whereas it was less than $30 \%$ at $\mathrm{pH}$ 9. This is an interesting feature, showing that the overall film composition can be selectively tuned by a change of the $\mathrm{pH}$ of the polymer solutions.

In Fig. 2, also in Figs. 3 and 4, the reflectometric outputs took sometimes a peculiar shape with a sharp increase and a slow decrease that lasted during most of the recording (about $10 \mathrm{~min}$ ). This was the case at $\mathrm{pH} 5.5$ for the adsorption of MADQUAT only (see also Figs. 3 and 4). These "overshoots" have been already discussed in the literature, mentioning two principal explanations, either a fast adsorption process followed by the dissolution of a polyelectrolyte complex [16] or a slow rearrangement of the polyelectrolyte in the layer, consecutive to the initial adsorption [8]. All experiments were repeated three times, with a confidence of the order of 5\%. Additional experiments have been carried out in order to understand the reason of the overshoot in our experimental conditions. This will be developed in an incoming paper.

Finally, we ought to comment the general shape of the reflectometric curves, showing a continuous increase of the step heights (i.e. deposited weights) in the successive layers, more clearly so at $\mathrm{pH}$ 4. This is a common feature in the construction of PEM, which was identified as an exponential growth $[20,21]$, at the difference with a linear growth when the uptake 


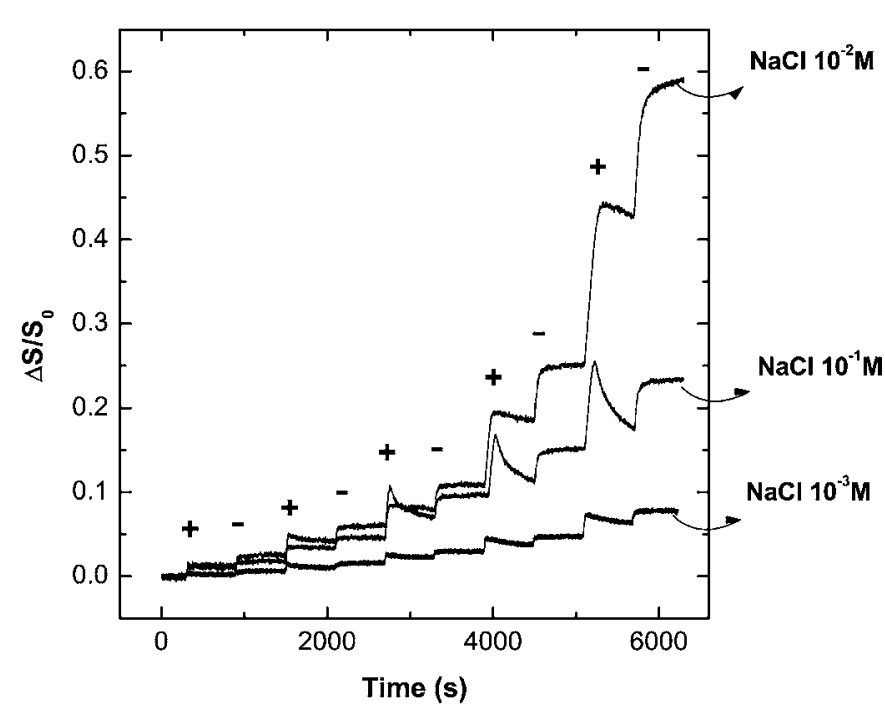

(a)

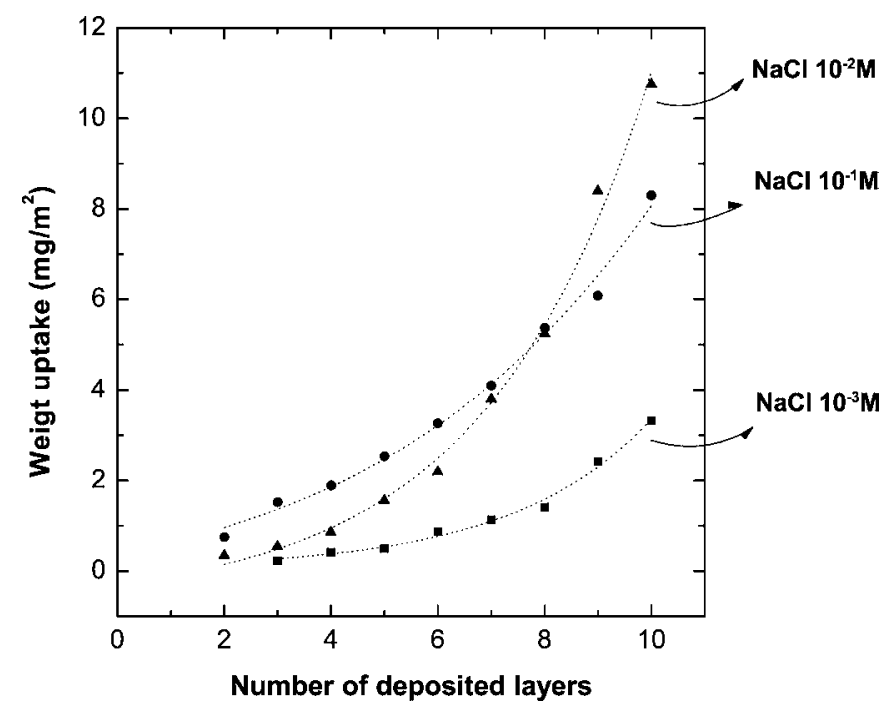

(b)

Fig. 3. Successive uptakes on silicon oxide of MADQUAT and PAA at various $\mathrm{NaCl}$ concentrations $\left(10^{-3}, 10^{-2}, 10^{-1} \mathrm{M}\right)$. Polyelectrolyte concentration: $0.01 \mathrm{~g} \mathrm{~L}^{-1}, \mathrm{pH}$ 5.5. (a) Output of the reflectometer, (b) weight uptake $\left(\mathrm{mg} \mathrm{m}^{-2}\right)$

remains constant for each polymer in each step. The reason for the two different kinds of growth is not clear, and possibly not single. It has been explained that such a phenomenon required the diffusion of at least one of the polymers through the whole film [22], or that it derived from the formation of a diffuse interface due to the weakness of the macromolecular complexes [23]. In the present investigation we shall explain in our discussion that there are actually two different regimes in the stepwise growth of the film, one in the lower steps where the growth is dominated by the influence of the surface and one in the higher steps where the uptake results from the polymer/polymer interactions.

\subsection{Ionic strength dependence}

The dependence of the multilayer growth on the concentration of $\mathrm{NaCl}$ is shown at $\mathrm{pH} 5.5$ in Fig. 3 and in Table 2. The

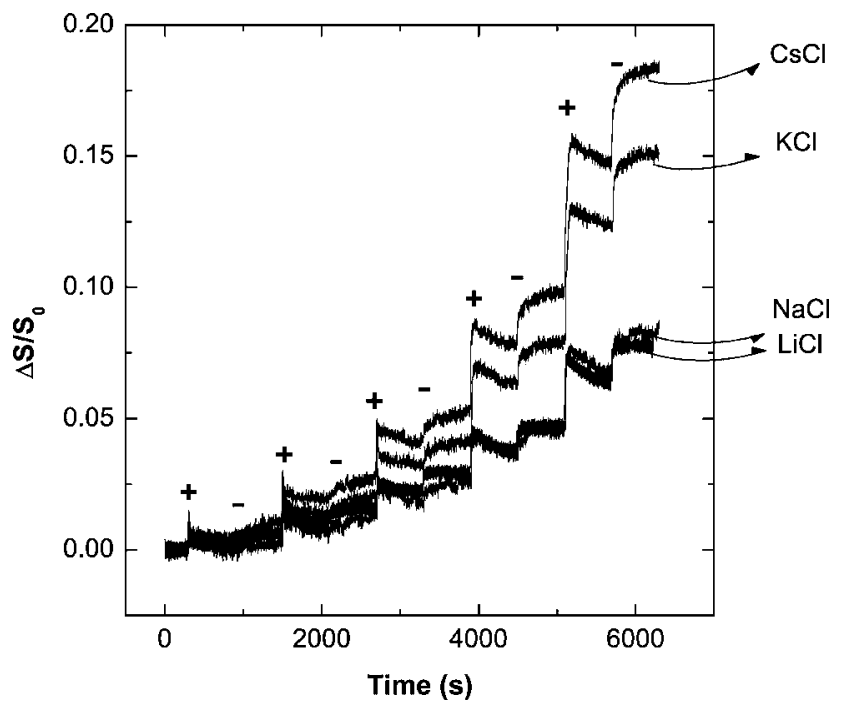

(a)

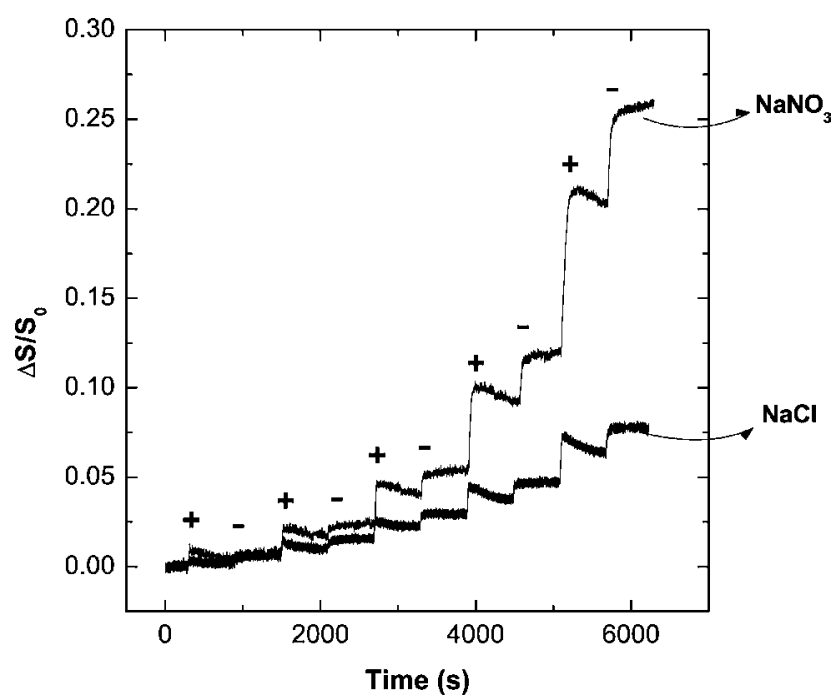

(b)

Fig. 4. Effect of monovalent cations (a) and anions (b) onto MADQUAT/PAA multilayer adsorption. Experimental parameters: polyelectrolyte concentration $0.01 \mathrm{~g} \mathrm{~L}^{-1}$, salt concentration $10^{-3} \mathrm{M}$.

figure presents both the output of the reflectometer (Fig. 3a) and the successive weight uptakes (Fig. 3b), showing that uptake did not follow linearly from the output in this case. The phenomenon was caused by the effect in the measurements of the difference in the refractive index between solutions [15]. The general trends of the reflectometric plots in Fig. 3a resemble that in Fig. 2, with a strong accentuation of the overshoots for the deposition of MADQUAT. Note that the plot at pH 5.5 in Fig. 2 corresponds to the plot at $10^{-3} \mathrm{M}$ in Fig. 3. As expected from other investigations [24] the film growth was much lower in $\mathrm{NaCl} 10^{-3} \mathrm{M}$ solutions, which resulted from a lower screening of the repulsive interactions between charged segments along the chain backbone. The lower electrostatic screening had indeed two consequences, first macromolecules stretched out and took more space on the surface, second an electrostatic barrier was raised at lower uptake from solutions with lower salt concentration, preventing additional 
Table 2

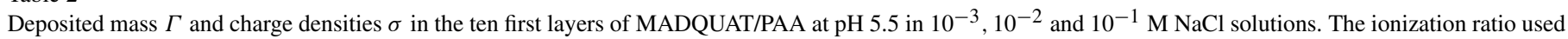
to calculate the charge density of PAA is 0.5 in all cases

\begin{tabular}{|c|c|c|c|c|c|c|}
\hline \multirow{3}{*}{$\begin{array}{l}\text { Layer } \\
\text { number }\end{array}$} & \multicolumn{6}{|l|}{$\mathrm{NaCl}$} \\
\hline & \multicolumn{2}{|l|}{$10^{-3} \mathrm{M}$} & \multicolumn{2}{|l|}{$10^{-2} \mathrm{M}$} & \multicolumn{2}{|l|}{$10^{-1} \mathrm{M}$} \\
\hline & $\overline{\Gamma\left(\mathrm{mg} \mathrm{m}^{-2}\right)}$ & $\overline{\sigma\left(\mathrm{Cm}^{-2}\right)}$ & $\Gamma\left(\mathrm{mg} \mathrm{m}^{-2}\right)$ & $\overline{\sigma\left(\mathrm{Cm}^{-2}\right)}$ & $\overline{\Gamma\left(\mathrm{mg} \mathrm{m}^{-2}\right)}$ & $\sigma\left(\mathrm{Cm}^{-2}\right)$ \\
\hline 1 & 0.063 & +0.030 & 0.207 & +0.099 & 0.53 & +0.25 \\
\hline 2 & 0.078 & -0.041 & 0.136 & -0.136 & 0.22 & -0.12 \\
\hline 3 & 0.091 & +0.044 & 0.197 & +0.095 & 0.77 & +0.37 \\
\hline 4 & 0.185 & -0.098 & 0.315 & -0.168 & 0.37 & -0.20 \\
\hline 5 & 0.078 & +0.038 & $0.703^{\mathrm{a}}$ & +0.338 & $0.65^{\mathrm{a}}$ & +0.31 \\
\hline 6 & 0.38 & -0.201 & 0.63 & -0.336 & 0.73 & -0.39 \\
\hline 7 & $0.26^{\mathrm{a}}$ & +0.123 & 1.61 & +0.775 & 0.83 & +0.40 \\
\hline 8 & 0.28 & -0.150 & 1.43 & -0.763 & 1.26 & -0.67 \\
\hline 9 & 1.01 & +0.487 & 3.16 & +1.52 & 0.71 & +0.34 \\
\hline 10 & 0.91 & -0.482 & 2.36 & -1.25 & 2.23 & -1.18 \\
\hline \multicolumn{7}{|c|}{ Total weights $\left(\mathrm{mg} \mathrm{m}^{-2}\right)$} \\
\hline MADQUAT & 1.5 & & 5.9 & & 3.5 & \\
\hline PAA & 1.8 & & 4.9 & & 4.8 & \\
\hline Total & 3.3 & & 10.8 & & 8.3 & \\
\hline
\end{tabular}

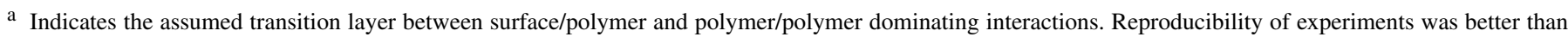
$5 \%$ in all cases.

macromolecules to reach the surface. A more complicate trend showed up at higher salt concentrations $\left(10^{-2}\right.$ and $10^{-1} \mathrm{M}$ $\mathrm{NaCl}$ ). Lower deposits were formed in the early part of the build-up ( 3 first bilayers) in $10^{-2} \mathrm{M}$ than in $10^{-1} \mathrm{M} \mathrm{NaCl}$ solutions, and reversely in subsequent layers. Overall (see Table 2) the uptake was less in $10^{-1} \mathrm{M}\left(8.3 \mathrm{mg} \mathrm{m}^{-2}\right)$ than in $10^{-2} \mathrm{M}\left(10.8 \mathrm{mg} \mathrm{m}^{-2}\right) \mathrm{NaCl}$ solutions. In the discussion we shall explain the phenomenon by a change of the determining influence in the uptake from the MADQUAT/surface interaction at low coverage to that of MADQUAT with PAA once the silicon oxide surface was totally covered in subsequent layers. The adsorption of MADQUAT exhibited overshoots in the reflectometric signals at $\mathrm{pH}$ 5.5. Overshoots, which are an occasional feature of reflectometric measurements, were discussed in several papers $[16,23,25,26]$. Experiments performed in the two latter works revealed the subsequent dissolution of polymer complexes formed during an early stage of adsorption. Another explanation was based on the rearrangement of the polyelectrolytes in the adsorbed layer [8]. In the event of overshoots we calculated the uptake in Fig. 3 at the lower stationary output after the peak [18]. Another feature in the comparison between $\mathrm{NaCl}$ solutions $10^{-2}$ and $10^{-1} \mathrm{M}$ is that in the first case the adsorption of MADQUAT increased more or less regularly in the three last steps whereas it was roughly constant $(0.65-$ $0.77 \mathrm{mg} \mathrm{m}^{-2}$ ) in the second case. The possible explanation is that in $10^{-1} \mathrm{M}$ solutions PAA adsorbed as dense coils neutralized with $\mathrm{Na}^{+}$counterions. Instead all $-\mathrm{COOH}$ and $-\mathrm{COO}^{-}$ groups of PAA were able to bind with MADQUAT in $10^{-2} \mathrm{M}$ solutions, leading to a progressive and correlated increase of adsorption for the two polymers.

\subsection{Effects of salt type}

Build-up experiments were made in $10^{-3} \mathrm{M}$ solutions of different salts in order to investigate the specific effect of coun- terions in the polymer binding. Fig. 4 shows an increase of deposits in the order $\mathrm{Li}^{+}$to $\mathrm{Cs}^{+}$(a), and $\mathrm{Cl}^{-}$to $\mathrm{NO}_{3}^{-}$(b), which is in line with the Hofmeister series [27]: less hydrated ions are better at screening electrostatic repulsion forces, which allows more adsorption of macro-ions. The nature of counterions was already reported as a significant parameter in LBL deposits. In the case of poly(diallyldimethyl ammonium chloride)-PDADMA/poly(sodium 4-styrenesulfonate)PSS Salomaki et al. [28] found a strong increase of the thickness and roughness of 10 bilayers films from $\mathrm{F}^{-}$to $\mathrm{Br}^{-}$in accordance with the Hofmeister series. Using the same polyelectrolytes, Dubas and Schlenoff [29] found a similar Hofmeister dependence of the film thickness due to the cations. Kovacevic et al. [23] using poly(dimethylaminoethyl methacrylate) with either poly(allylamine hydrochloride) or poly(acrylic acid) found that the polymer films were more stable in the presence of chloride than nitrate and phosphate ions. With respect to our purpose in the present study the occurrence of the Hofmeister series emphasizes the determining contribution of small ions in the construction of LBL polymer films.

\subsection{Morphology of multilayers}

The build-up of the LBL films was also followed with atomic force microscopy. Fig. 5 shows representative examples of images of 5 bilayers deposited at pH 5.5 in solutions of different $\mathrm{NaCl}$ concentration. Images refer to the same experiments as those leading to Fig. 3 and Table 2. They show a heterogeneous surface with bumps that increase in size and frequency with the ionic strength. The bumps reveal the areas of more favorable growth, they developed at the location of the polymer complexes formed in the first bilayer. The phenomenon was already described by Picart et al. [30] in the case of LBL films made with poly(L-lysine) and hyaluronic acid. In the present case bumps increased in height between an average of 5 and 20 


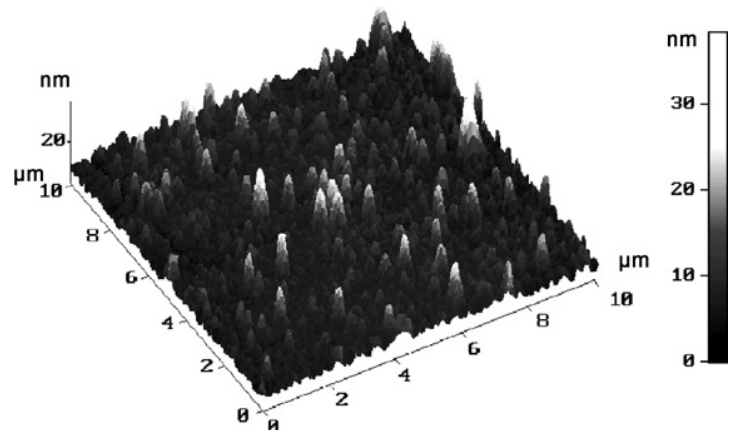

(a)

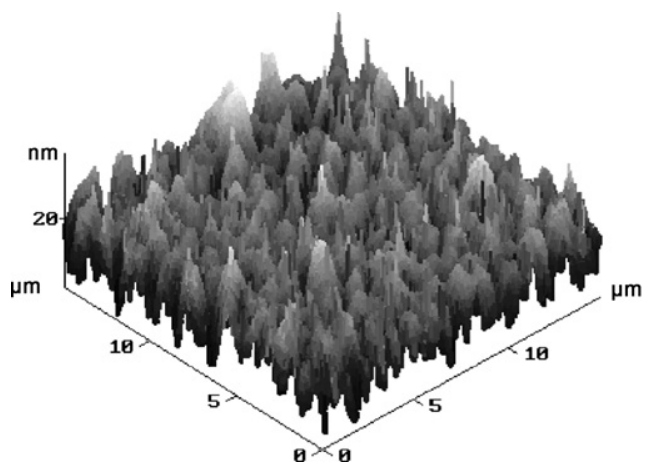

(b)
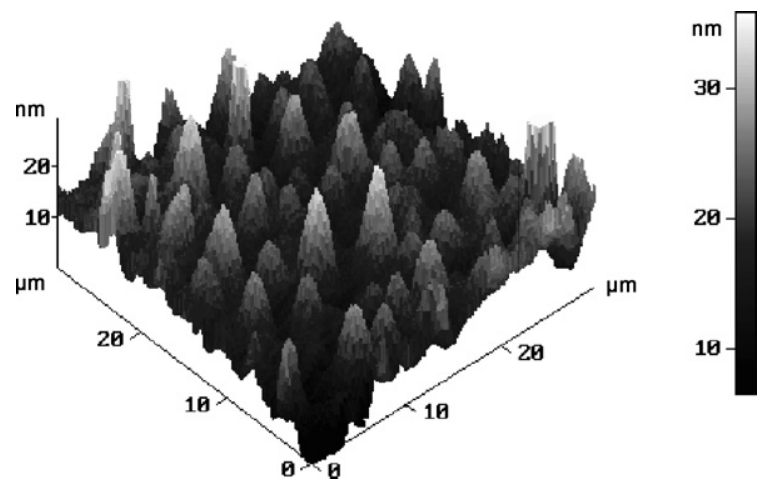

(c)

Fig. 5. AFM images after five MADQUAT/PAA bilayer deposition at $\mathrm{pH} 5.5$ and for various $\mathrm{NaCl}$ concentrations: (a) $10^{-3} \mathrm{M}\left(10 \times 10 \mu \mathrm{m}^{2}\right)$, (b) $10^{-2} \mathrm{M}$ $\left(15 \times 15 \mu \mathrm{m}^{2}\right)$ and $(\mathrm{c}) 10^{-1} \mathrm{M}\left(30 \times 30 \mu \mathrm{m}^{2}\right)$.

$\mathrm{nm}$ and decreased in number with an increase of the salt concentration, which follows the increase of the deposited weight (be aware of the different scales of the scanned areas in the images). Our pictures point again to the large heterogeneity of LBL films which may be seen as a surface influenced coalescence of polymer complexes, instead of a stochastic coacervation as it takes place in the bulk solution [26,31]. Certainly, the process of building LBL polyelectrolyte films closely resembles the formation of insoluble complexes in the bulk solution [31,32].

\subsection{Charge balance and discussion}

Polyelectrolyte adsorption is essentially promoted and limited by electrostatic interactions. In the case of a single adsorption layer, a given polyion adsorbs on a surface with an opposite charge up to slightly above charge equivalence. Practically, when adsorption is completed at maximum coverage the zeta potential reaches about $\pm 40 \mathrm{mV}$ in solutions with low salt concentration. Theoretical studies provide satisfactory understanding of the adsorption process [33]. One of the major features found in theories is that the adsorption of polyions is limited kinetically, which is due to electrostatic interactions between the adsorption layer, once an excess of charge has accumulated, and incoming macromolecular segments $[33,34]$. In accordance with experimental results we deduce that $\pm 40 \mathrm{mV}$ is the barrier above which charged polymer units can no longer cross the interface. In other words in many cases the adsorption of charged macromolecules does not reach thermodynamic equilibrium [25]. A number of experimental artifacts in adsorption isotherms were indeed explained by the kinetic limitation of adsorption, one of them is a lack of reversibility of the uptake when changing the experimental variables $(\mathrm{pH}$, polymer concentration, ionic strength) or the adsorption procedure [34-36].

In the case of successive adsorptions, as in the case of self assembly of polyelectrolyte films, the rules for single adsorption should remain valid, but their application is more complicated and poorly discussed in the literature. We shall attempt in the following discussion to show that a large part of our results can be understood on the grounds of electrostatic interactions.

In a former paper addressing the growth of self assembled films with poly(allylamine, $\mathrm{HCl}$ ) and poly(styrene sulfonate), further named PAH/PSS, the charge balance was calculated step by step in the three first bilayers, showing that uncovered parts of the silica substrate were still active in the adsorption of the polycation up to the third PAH deposit and about $70 \%$ of the charge density of the strong polyacid (PSS) was neutralized by co-adsorbed $\mathrm{Na}^{+}$counterions in the first and second PSS deposition steps. In other words, $70 \%$ of the sulfonate groups did not actually bind with the aminated groups of PAH [12].

In the present study we dealt with the opposite case, a strong base (MADQUAT) and a weak acid (PAA), but we found similarities in the build-up mechanism. Thus, the construction of the film started with the adsorption of the polycation on silicon oxide, which was negatively charged. The charge density of silicon oxide varies strongly with $\mathrm{pH}$, as reported in Table 1, it is almost zero below $\mathrm{pH} 6$ and about $-0.06 \mathrm{C} \mathrm{m}^{-2}$ at $\mathrm{pH} 9$ [37]. As expected from the principle of charge compensation, the adsorption of MADQUAT increased with $\mathrm{pH}$ and we see indeed at $\mathrm{pH} 9\left(10^{-3} \mathrm{M} \mathrm{NaCl}\right.$ solution) that the uptake was of the order of that required for charge balance ( $20 \%$ above, Table 1). Reflectometric measurements were not very accurate in the first layers, however uptake values recorded in the whole investigation looked consistent with each other and with respect to the expected influence of the $\mathrm{pH}$ and the salt content. In the charge balance we may systematically neglect the charge excess corresponding to the zeta potential $( \pm 40 \mathrm{mV})$ after polymer adsorption, since it is of the order of $3 \times 10^{-3} \mathrm{Cm}^{-2}$ (as calculated with the Gouy-Chapman relationship for the diffuse layer model [38]). In our opinion the calculated $20 \%$ excess of positive charge after the first MADQUAT deposit was larger than uncertainties, it was actually compensated by an increase 
of the surface charge of silicon oxide due to the interaction with MADQUAT and to the co-adsorption of $\mathrm{Cl}^{-}$counterions. At pH 4 and 5.5 where silicon oxide was very slightly or not charged at all, the significant adsorption of MADQUAT revealed the existence of a specific (non-coulombic) bonding of the polymer with the silicon oxide surface. This was frequently encountered between silicon oxide and macromolecules containing basic groups such as poly(vinylimidazole) [38]. The specific bond may also consist in hydrogen bonding between the carbonyl groups of MADQUAT and the silanol groups. At $\mathrm{pH} 4$ and 5.5 the charge neutralization in the first $\mathrm{SiO}_{2}-$ MADQUAT layer resulted partly from the induced ionization of silicon oxide (as said earlier the actual ionization $\mathrm{p} K$ of surfaces and weak polyelectrolytes is very sensitive to the local ionic environment [19] and partly from the co-adsorption of chloride ions). Practically, the additional ionization of silicon oxide upon adsorption of a positive polymer was ascertained and quantified in a former paper from the decrease of $\mathrm{pH}$ consecutive to the addition of PAH in a colloidal suspension of silica [12].

When PAA was deposited in the second step it could only bind with the formerly deposited MADQUAT units after displacement of part of the chloride counterions, forming macromolecular complexes that showed up as bright spots in AFM pictures. PAA did not adsorb directly on silicon oxide, as shown by Zaman et al. [39] and proved with our materials by complementary experiments. In line with the general rule for polyelectrolyte adsorption, PAA adsorbed up to the rise of the kinetic barrier. Interestingly, Table 1 shows a satisfying charge balance after completion of the first bilayer $\left(\mathrm{pH} 4:+0.019 \mathrm{Cm}^{-2} /\right.$ $-0.015 ; \mathrm{pH} 5.5$ : $+0.03 /-0.04 ; \mathrm{pH} 9$ : $+0.074 /-(0.06+$ $0.016)$ ). The difference was well within experimental uncertainties and two unquantified phenomena: (i) part of the neutralization came from the co-adsorbed small ions, (ii) the increase of the ionization ratio of both the silicon oxide surface and PAA upon interaction with an opposite charge.

In the third step, MADQUAT molecules could bind both with the free carboxylate groups protruding from the macromolecular complexes and with the silanol groups on the bare part of silicon oxide since, as explained earlier, the rise of an electrostatic barrier left a significant part of the surface free of polymer. The uptake in the second MADQUAT layer was again limited by electrostatic interactions, which explains that values resemble those in the first layer, more so at $\mathrm{pH}$ 9. The binding process continued in the next step (fourth layer) where PAA bound with the MADQUAT groups protruding from preformed polymer aggregates and, in addition, PAA formed new complexes with the isolated MADQUAT molecules on the surface. Thus, this early growth mechanism features two principal phenomena, the alternate formation and growth of polymer aggregates upon PAA deposits and the increase of the silicon oxide coverage upon MADQUAT deposits.

The above process continued in subsequent layers until the point when the entire silicon oxide surface was covered by MADQUAT molecules. At this stage the adsorption was only determined by interactions between polyelectrolyte molecules. Some investigators have already suggested that a transition of this kind may explain the change of growth rate in successive steps [40]. Experimentally, in the case of PAH/PSS polymer films made on colloidal silica, we have seen from the $\mathrm{pH}$ drop consecutive to the adsorption of the polycation PAH that the silica surface was still active in adsorption up to the third bilayer (i.e. the third deposition of PAH) [12]. Also, in the case of $\mathrm{PLL}^{+} / \mathrm{HA}^{-}$Picart et al. [30] found, from the comparison between AFM pictures and successive deposited weights measured with a quartz microbalance, a complete surface coverage after deposition of 8 bilayers. In the present case some data clearly exhibit a change of growth regime. At $\mathrm{pH} 5.5$, where the charge density of the silicon oxide surface was more sensitive to the adsorption of MADQUAT, the charge densities of the two polymers started to equilibrate in bilayers 4 and 5 for $\mathrm{NaCl}$ solutions $10^{-3} \mathrm{M}$ (Table 1) and in bilayers 3, 4 and 5 for $\mathrm{NaCl}$ solutions $10^{-2} \mathrm{M}$ (Table 2). At pH $9\left(10^{-3} \mathrm{M} \mathrm{NaCl}\right.$ solutions, Table 1) the change between surface/polymer and polymer/polymer determining interactions seemed to take place at the third bilayer when MADQUAT and PAA equilibrated their respective charge. In the two first bilayers MADQUAT and PAA each repeatedly adsorbed the same amount. In the case of MADQUAT the adsorption was ruled by the charge density of silicon oxide, in the case of PAA by the excess of charge of the prior MADQUAT layer. Finally, at pH 4 the charge densities equilibrated approximately each other up to the fourth bilayer, which was to be expected since the silicon oxide surface was not charged.

The influence of the ionic strength features a remarkable trend in weight and charge balances. In $10^{-1} \mathrm{M} \mathrm{NaCl}$ solutions, MADQUAT adsorbed more than in $10^{-2} \mathrm{M}$ solutions only in the first two bilayers, which we attribute to the effect of charge screening when the silicon oxide/MADQUAT interaction prevailed. In further bilayers the uptake was the same in $10^{-2}$ and $10^{-1} \mathrm{M}$ solutions and remained also constant in successive steps between 0.64 and $0.82 \mathrm{mg} \mathrm{m}^{-2}$ (i.e., 0.31 and $0.39 \mathrm{C} \mathrm{m}^{-2}$ ), whereas that of PAA increased stepwise progressively but remained the same in corresponding steps between $10^{-1}$ and $10^{-2} \mathrm{M}$ solutions. As a consequence, the charge density of the PAA layers in $10^{-1} \mathrm{M}$ solutions was largely in excess of that of the preceding MADQUAT layer $(+0.31 /-0.39 ;+0.40 /-0.67 ;+0.34 /-1.18$ in bilayers 3,4 and 5, respectively). Obviously in higher step numbers when polymer-polymer interactions prevailed, a large part of the carboxylate groups of PAA were inaccessible to MADQUAT segments. They formed coils and loops neutralized with coadsorbed $\mathrm{Na}^{+}$ions. Nevertheless, the total weight and composition of the film were nearly the same after bilayer 5 . This observation may be of practical interest for controlling the fabrication of films with a variable amount of exchangeable anionic sites.

AFM images made at pH 5.5 supported the growth mechanism as outlined above. They reveal the effect of the salt concentration on the morphology of the polymer film. In $10^{-3} \mathrm{M} \mathrm{NaCl}$ solutions the electrostatic barrier was raised at low polymer deposits, leading to thin polymer films with a low number of small aggregates (small peaks). Increasing the salt concentration caused an increase of the size of the 
aggregates with a diminution of their number, which is attributed to a coalescence of complexes as suggested by Picart et al. [30].

\section{Conclusion}

The early step by step construction of LBL films with the weak polyanion PAA and the strong polycation MADQUAT depends strongly on $\mathrm{pH}$, salt type and salt concentration. The general trend of growth divided into two parts, in the first part (two to three first bilayers) the silicon oxide substrate had a significant influence on the magnitude of adsorption of MADQUAT, in the second part the growth was ruled only by the interactions between the two polymers.

The total film weight ( 5 bilayers) decreased about 7 times between $\mathrm{pH} 4$ and 5.5 and similarly between $\mathrm{pH} 5.5$ and 9, in addition the polymer composition changed from about $65 \mathrm{wt} \%$ PAA at $\mathrm{pH} 4$ to $35 \mathrm{wt} \%$ PAA at $\mathrm{pH}$ 9. However the positive/negative charge balance was approximately respected in the successive bilayers, showing that the polymer uptake was limited kinetically by the raising of an electrostatic barrier. Deviations to the charge stoichiometry in the successive bilayers were in the range of uncertainties due to unquantified variations of charge densities upon interactions between surface and polymers, and to the incorporation of electrolyte ions in the polymer film.

Different kinds of interactions were involved in the growth of the polymer films. At $\mathrm{pH} 4$ and 5.5 the first MADQUAT layers bound with silicon oxide via non electrostatic interactions (certainly hydrogen bonding with the silanol groups), whereas coulombic interactions prevailed at $\mathrm{pH}$ 9. Binding interactions between MADQUAT and PAA involved hydrogen bonding at lower $\mathrm{pH}$ and electrostatic bonds at higher $\mathrm{pH}$. The influence of salt was patent but rather complicated to rationalize. At the end, the deposited film weight was slightly lower in $\mathrm{NaCl}$ solutions $10^{-1}$ than $10^{-2} \mathrm{M}$ at $\mathrm{pH} 5.5$, but the charge balance revealed a larger ratio of the charge compensation of PAA with $\mathrm{Na}^{+}$ions in the first case. The important role of small ions in the construction of the film was also emphasized by the occurrence of Hofmeister trends for both negative and positive monovalent ions.

The growth mechanism lead to a very heterogeneous film structure, exhibiting bumpy islands with a size and a number that depended on the growth conditions. This heterogeneity was explained by a growth process with three major features. First the growth starts as a localized coacervation process by adsorption of PAA on primarily deposited MADQUAT molecules on the silicon oxide surface. Second, from these discrete sites the growth continues in the first bilayers in two ways, MADQUAT increases the bi-dimensional primary coverage of silica and PAA increases the number of coacervation sites. Third, in later stages the build-up of the film follows only from polymer/polymer interactions, forming polyelectrolyte complexes with different morphologies, depending on $\mathrm{pH}$ and salt concentration. From our data, two to three bilayers were required to cover the silica surface entirely. A more detailed description of the influence of the physical parameters on the film morphol- ogy, in relation with the growth rate in this system will be given in an incoming report.

\section{References}

[1] G. Decher, J.D. Hong, Makromol. Chem. Macromol. Symp. 46 (1991) 321.

[2] G. Decher, J.D. Hong, J. Schmitt, Thin Solid Films 210/211 (1992) 831.

[3] G. Decher, J.B. Schlenoff, Multilayers Thin Films, Wiley-VCH, Weinheim, 2003.

[4] P. Bertrand, A. Jonas, R. Legras, Macromol. Rapid Commun. 21 (2000) 319.

[5] M. Schönhoff, Curr. Opin. Colloid Interface Sci. 8 (2003) 86.

[6] V. Bosio, F. Dubreuil, G. Bogdanovic, A. Fery, Colloids Surf. A 243 (2004) 147.

[7] G. Ladam, P. Schaad, J.-C. Voegel, P. Schaaf, G. Decher, F. Cuisinier, Langmuir 16 (2000) 1249.

[8] L. Wågberg, G. Pettersson, S. Notley, J. Colloid Interface Sci. 274 (2004) 480.

[9] K. Lowack, C.A. Helm, Macromolecules 31 (1998) 823.

[10] V.V. Belyaev, A.L. Tolstikhina, N.D. Stepina, R.L. Kayushina, Cryst. Rep. 43 (1998) 124.

[11] Z. Tang, S.T. Donohoe, J.M. Robinson, P.A. Chiarelli, H. Wang, Polymer 46 (2005) 9043.

[12] J. Dejeu, L. Buisson, M.C. Guth, C. Roidor, F. Membrey, D. Charraut, A. Foissy, Colloids Surf. A 288 (2006) 26.

[13] J.C. Dijt, M.A. Cohen Stuart, G.J. Fleer, Adv. Colloid Interface Sci. 50 (1994) 79.

[14] T. Roques-Carmes, F. Membrey, C. Filiâtre, A. Foissy, J. Colloid Interface Sci. 245 (2002) 257.

[15] C.C. Buron, C. Filiâtre, F. Membrey, H. Perrot, A. Foissy, J. Colloid Interface Sci. 296 (2006) 409.

[16] D. Kovacevic, S. van der Burgh, A. de Keizer, M.A. Cohen Stuart, Langmuir 18 (2002) 5607.

[17] C.C. Buron, F. Membrey, C. Filiâtre, A. Foissy, Colloids Surf. A 289 (2006) 163.

[18] C. Buron, Ph.D. thesis, University of Franche-Comte (2004).

[19] S. Ulrich, M. Seijoa, S. Serge Stoll, Curr. Opin. Colloid Interface Sci. 11 (2006) 268.

[20] R.A. McAloney, M. Sinyor, V. Dudnik, M.C. Goh, Langmuir 17 (2001) 6655.

[21] J. Ruths, F. Essler, G. Decher, H. Riegler, Langmuir 16 (2000) 8871.

[22] C. Picart, J. Mutterer, L. Richert, Y. Luo, G.D. Prestwich, P. Schaaf, J.-C. Voegel, P. Lavalle, Proc. Natl. Acad. Sci. USA 99 (2002) 12531.

[23] D. Kovacevic, S. van der Burgh, A. de Keizer, M.A. Cohen Stuart, J. Phys. Chem. B 107 (2003) 7998.

[24] E. Leontidis, Curr. Opin. Colloid Interface Sci. 7 (2002) 81.

[25] N.G. Hoogeveen, M.A. Cohen Stuart, G.J. Fleer, M.R. Bohmer, Langmuir 12 (1996) 3675

[26] S.A. Sukhishvili, E. Kharlampieva, V. Izumrudov, Macromolecules 39 (2006) 8873.

[27] F. Hofmeister, Arch. Exp. Pathol. Pharmakol. 27 (1890) 395

[28] M. Salomaki, P. Tervasmaki, S. Areva, J. Kankare, Langmuir 20 (2004) 3679.

[29] S.T. Dubas, J.B. Schlenoff, Macromolecules 32 (1999) 8153

[30] C. Picart, P. Lavalle, P. Hubert, F.J.G. Cuisinier, G. Decher, P. Schaaf, J.-C. Voegel, Langmuir 17 (2001) 7414.

[31] V. Kabanov, in: G. Decher, J.B. Schlenoff (Eds.), Multilayer Thin Films, Wiley-VCH, Weinheim, 2003, p. 47.

[32] T. Farhat, G. Yassin, S.T. Dubas, J.B. Schlenoff, Langmuir 15 (1999) 6621.

[33] G.J. Fleer, M.A. Cohen Stuart, J.M.H.M. Scheutjens, T. Cosgrove, B. Vincent, Polymers at Interfaces, Chapman and Hall, London, 1993.

[34] C. Geffroy, M.P. Labeau, K. Wong, B. Cabane, M.A. Cohen Stuart, Colloids Surf. A 172 (2000) 47.

[35] T. Roques-Carmes, S. Aouadj, C. Filiâtre, F. Membrey, A. Foissy, J. Colloid Interface Sci. 274 (2004) 421.

[36] T. Roques-Carmes, F. Membrey, A. Deratani, M. Boehmer, A. Foissy, J. Colloid Interface Sci. 256 (2002) 273. 
[37] J. Persello, in: E. Papirer (Ed.), Adsorption on Silica Surfaces, 2000, p. 297.

[38] M.R. Böhmer, W.H.A. Heesterbeek, A. Deratani, E. Renard, Colloids Surf. A 99 (1995) 53.
[39] A.A. Zaman, R. Tsuchiya, B.M. Moudgil, J. Colloid Interface Sci. 256 (2002) 73 .

[40] T. Radeva, V. Milkova, I. Petkanchin, Colloids Surf. A 209 (2002) 227. 